\title{
The horizon of medical attention in pediatrics: What to do in the case of children who are in abandonment, conflict, harm, or danger situations in combination with a severe disease?
}

\author{
Jessica H. Guadarrama-Orozco', Guillermo R. Cantú-Quintanilla², Diana Ávila-Montiel'1, \\ Myriam Altamirano-Bustamante ${ }^{3}$, Ingris Peláez-Ballestas ${ }^{4}$, Cristina Caballero-Velarde², Luis E. Juárez-Villegas ${ }^{1}$, \\ Nahúm de la Vega-Morell ${ }^{5}$, Javier Kelly-Garcia ${ }^{6}$, Adalberto de Hoyos-Bermea ${ }^{7}$, Elisa Dorantes-Acosta ${ }^{1}$, \\ José D. Gamboa-Marrufo ${ }^{1 \dagger}$, Onofre Muñoz-Hernández ${ }^{1,8}$, and Juan Garduño-Espinosa ${ }^{1,8 *}$ \\ ${ }^{1}$ Hospital Infantil de México Federico Gómez; ${ }^{2}$ Universidad Panamericana; ${ }^{3}$ Instituto Mexicano del Seguro Social; ${ }^{4}$ Hospital General de México; \\ ${ }^{5}$ Instituto Panamericano de Alta Dirección de Empresas; ${ }^{6}$ Hospital de Oncología, Centro Médico Nacional Siglo XXI, IMSS; ${ }^{7}$ Instituto Politécnico \\ Nacional; ${ }^{8}$ Universidad Nacional Autónoma de México. Mexico City, Mexico
}

\begin{abstract}
Background: Laws refer that minors do not have the capability to give informed consent for their own medical attention. However, there are special conditions in which they are allowed to decide about their health. The greater the judgment and experience limitations in minors, the less weight is given to the values and objectives they express. Furthermore, the more adverse consequences might be, the higher the level of authority that is demanded to decide on behalf of the minor, thus granting the state the capability to guarantee the well-being of the minor. Case report: A 12-year-old female patient was presented with a diagnosis of acute lymphoblastic leukemia, with precarious social and family background; evolution of the disease obstructed by the disregard of the treatment due to her unsanitary and extreme poverty conditions. Both of her parents died soon after the start of the treatment, and she was kept under the care of her half-sister of legal age. The work and the ethical dilemma of the pediatrician and the staff of Hospital Infantil de México Federico Gómez are exposed within the building of support networks with the objective of prioritizing the minor's well-being, without allowing family break-up or disintegration, thus succeeding in her recovery. Conclusions: The case was submitted to the Hospital Bioethics Committee. Interinstitutional support networks were built to improve dynamics of the family, thus solving the needs of the minor. Despite the misfortune of the situation, the disease was successfully overcome.
\end{abstract}

Key words: Bioethics issues. Clinical ethics. Clinical ethics committees. Medical ethics.

\section{Correspondence:}

*Juan Garduño-Espinosa

E-mail: juan.gardunoe@gmail.com jgarduno@ himfg.edu.mx
Date of reception: 10-10-2017

Date of acceptance: 19-12-2017

DOI: 10.24875/BMHIME.M18000036
Available online: 14-11-2018 Bol Med Hosp Infant Mex. 2018;75:144-154 www.bmhim.com

2444-3409/@ 2018. Hospital Infantil de México Federico Gómez, published by Permanyer México SA de CV, all rights reserved. 


\section{El horizonte de la atención médica en pediatría: ¿qué hacer en el caso de niños que se encuentran en situación de abandono, conflicto, daño o peligro, aunado a una enfermedad grave?}

\section{Resumen}

Introducción: Las leyes refieren que los menores no tienen la capacidad para dar su consentimiento informado para su propia atención médica; sin embargo, hay condiciones especiales en las que se les permite determinar lo referente a su salud. Cuanto mayor sean las limitaciones de juicio y experiencia en los menores, menos peso se otorga a los valores $y$ objetivos que expresan; cuanto más adversas sean las consecuencias, se deberá exigir un nivel más alto de autoridad para decidir en nombre del menor, dejando al Estado la capacidad de garantizar el bienestar del menor. Caso clínico: Niña de 12 años con diagnóstico de leucemia linfoblástica aguda LI, con antecedentes familiares y sociales precarios; evolución entorpecida por el desapego al tratamiento y sus condiciones insalubres y pobreza extrema. Ambos padres fallecieron al poco tiempo de iniciar su tratamiento, quedando ella al cuidado de su medio hermana mayor de edad. Se exponen la labor y el dilema ético del oncólogo tratante y del personal del Hospital Infantil de México Federico Gómez en la creación de redes de apoyo con el objetivo de priorizar el bienestar de la menor, sin dar lugar al quebrantamiento y la desintegración familiar, consiguiendo exitosamente su recuperación. Conclusiones: El caso fue sometido al Comité de Bioética Hospitalaria. Se formaron redes de apoyo interinstitucionales para intervenir en la dinámica familiar, resolviendo los requerimientos de la menor, y se consiguió con éxito superar la enfermedad.

Palabras clave: Ética médica. Asuntos de bioética. Ética clínica. Comités de ética clínica.

\section{Introduction}

In pediatrics, a significant challenge is frequently presented, inherent to this practice and that derives from the impossibility for children to participate in a responsible manner in making decisions about their health and well-being. The vast majority of the problems in pediatrics arise in children who are mature enough to make it impossible to exclude them entirely from the decision process, but whose ability to make sure essential decisions is questionable.

The laws, in almost all the world, state that minors cannot give their informed and voluntary consent in their medical attention; however, there are special conditions that allow underage children to provide consent. The usual reason for these cases is to allow minors to seek and obtain treatment when it is likely that the requirement of the parent's consent and notification of the case discourages them from seeking treatment for their welfare. The children's capacity varies according to his growth and development; the different decisions related to medical care vary regarding the demands made to the person making the decisions. When dealing with complex situations, the compression and reasoning required are higher than when they are less risky and beneficial.

What is discussed is not whether the minor is capable of making decisions on his own; instead, what is in doubt is their ability to understand the consequences of the proposed treatment thoroughly, so that they can give their informed consent to that treatment. What is pursued is for the minor to understand the repercussions that these decisions will have on his present and future life.

There are three types of decision-making abilities: (a) communication and understanding of information, (b) reasoning, and (c) deliberation and the ability to apply a set of values or a conception of the good. Children under 12 years of age are more likely than adults or older children to see the locus of control as something external to them. Lewis ${ }^{1}$ discovered that children between 6 and 9 years old were often not perceived as making the decision, even when they were doing it. This point becomes relevant concerning voluntariness; if the minors see the locus of control as external, they will believe that the choice is not something that is in their hands and they will not resist the imposition of their own decisions by others. Between the ages of 7 and 13 years, they have given up magical thinking, but they still have trouble anticipating the future ${ }^{2}$.

Children learn that they must obey and authority figures (parents, doctors, and teachers) condition children $>14$ years old.

Perhaps the most important capacities for reasoning are those that Piaget called the stage of formal operations in cognitive development ${ }^{3}$. Around the age of five, children begin to explain with magical perspectives of the causality of diseases. It is not until 12 or 13 years of age that most of them start to understand 
"that there are multiple causes of disease, that the body can respond variably, and that host interacts with the agent to cause and cure the disease." In general, the development tests support the conclusion that minors, from 14 or 15 years old in general, have already developed the various faculties necessary to be able to make decisions that concern their medical care in a level more or less comparable to that reached by most adults.

There are also called subjective rules, which are of two types: (1) minor conditional, in which a child can give his consent if his life is in danger, and (2) mature child, who can give his consent if he understands the nature and purposes of the proposed treatment ${ }^{4}$.

The mature child's rule preserves the presumption that minors cannot consent to their treatment. To reject that presumption, the "maturity" of the child must be demonstrated; that is, the understanding of the nature and objectives of the proposed treatment in all cases. This rule has been restricted in almost all cases to those children who are very close to the legal age, usually never $<14$ years, regardless of the general faculties of that minor to decide.

Western laws sustain that every person, from birth to death, can exercise rights and be subject to obligations, which implies that, although one may lack the capacity to apply them, this does not mean that there is no legal personality. Therefore, it is understood that the law safeguards children rights until the individual reaches full capacity for their exercise ${ }^{5}$.

However, this capacity is not a matter of degrees but a threshold concept. Then, where or at what level of decision-making skills and the execution of a particular decision should this threshold be placed, so that it separates the capable of the incapable? In the case of children, given the legal presumption of disability, we should ask ourselves: how developed must be their aptitudes and performance to make decisions regarding a choice about their health so that this disability presumption is rejected and declared them capable of deciding for themselves? How to establish the level of aptitudes necessary to be able to make decisions in a non-arbitrary way (only set the chronological age as a limit)? The answer is that the appropriate level will be a balance of the central values at stake, self-determination, and the patient's well-being.

However, in children, a third substantial value is recognized: the interest of parents to make important decisions about the welfare of their children. Parents, who care about their children's well-being and know their needs better than anyone else, will be able to guarantee that the decisions made are for the welfare of their children. However, it does not mean that parents can impose their choice when it is not the best for their children because they are not their owners, they are their guardians. In the background, it is the parents who will face the consequences of the elections in the treatment of their children; therefore, it seems contradictory to force them to assume the implications of the therapy denying them the possibility of choosing. However, it is the child who assumes the main consequences of the choice; therefore, it is the well-being of the child that should primarily determine the choice.

Children are not owned by their parents and cannot do with them what they want; children are blank pages and only through a process of socialization and development will they acquire values, goals, and criteria, together with sufficient experience and the faculties to justify respect for their decisions.

The younger a child, the less weight we give to the preferences he expresses and his views on his good; the more significant the limitations of judgment and experience in children and adolescents, the less weight will be conferred to the values and objectives they express.

Substitution decisions correspond essentially to parents, because the family, as Dr. Diego Gracia says, is from its root an institution that has the right to provide content to the beneficence of the child, as long as the limit of non-maleficence is not breached. To make sure of this is an absolute function of the state ${ }^{6}$, from which it follows that the paternal authority is not absolute and when the welfare and life of the children are in danger, the state will have the responsibility to intervene.

The family is a valuable social institution; it is the context in which the children's faculties unfold for the intimate and social life. Due to this, the family must feel free of any outside control or intrusion; one aspect of this freedom is the right to make essential decisions about the welfare of its members who are still incapable.

Unlike adults, the well-being of children depends to a lesser extent on their personal preferences at the time and a greater extent on the objective conditions necessary to encourage their development and opportunities in the future. Parents are the supreme authority in determining the good of the child. Involving children in decisions about their treatment promotes their weIl-being since it increases their willingness to cooperate with the doctor and their family, which improves the evolution of the disease. 
Mexico signed the convention on the rights of the child on June 19, 1990, whose observance is mandatory by express provision of Article 133 of the General Constitution of the Mexican Republic, articles 2, 3, 9, 12,19 , and 20 of which 21 and 27 it is stipulated that the states involved will take all the appropriate measures to guarantee "... that the child is protected ...". Besides, the convention states that "... the interest of the child is a guiding principle in those who have responsibility for his education, health, and nutrition ...," but the principle of best interest applies to those subjects who are minors or temporarily incapable of having the potential for future moral consideration and are capable of developing faculties to become adults with self-determination.

With the exception of when the most basic interests of the children are at stake, a simple failure of the parents in their attempt to optimize the interest of the child will not be sufficient to trigger the justified intervention of a third party.

Thus, the principle of best interest should only serve as a regulative ideal - a guiding principle, not as a strict requirement, in situations in which the fundamental and primordial interests of a child (food, health, and education) are not at risk - since the parents own legitimate interests may come into conflict with doing what maximizes the child's welfare and may sometimes take priority over them. It is expected that parents make sacrifices for their children, but that does not force them to thwart they own more important interests when doing so could achieve an additional non-essential increase in benefit for their child.

Shoeman ${ }^{8}$ explains how unlikely it is that the principle of best interest strictly guides the decision of parents about their minor children: "it should be considered that the family is an intimate arrangement with its own goals and purposes [...] therefore, it would not be appropriate to impose on that arrangement [...] abstract liberal principles." It should not be understood that the principle of best interest, as a guiding principle for parental decisions, requires the literal optimization of the child's interest in all cases. Moreover, that the appropriate intervention principles will allow parents a wide margin of flexibility; that is, tolerate permissible separating or distancing from what could be the best for the child to protect the family from intrusions that would violate the privacy required to develop an intimate union, whose value for those who participate in it they depend on that intimacy. For example, choosing a religion different from the one that governs society (for example, Santeria), while not harming the child and community, could not be prevented from the family.

However, what is the threshold for state intervention in the care of the children? What is the correct moment in which the state can intervene with the parents in the guardianship of the child? When is it preferable to send a child to shelters or children's homes, instead of leaving them with their family? The most important variable will be associated with the particular consequences of the parents' choice for the well-being of the child, which can vary between clear and substantially beneficial (for example, avoiding serious and irreversible disability or permanent loss of health, basic education, beliefs, and religion), up to seriously harmful situations (death). The more adverse the expected consequences for the child, the more reasonable it will be to demand a higher level of intervention when the decisions of the parents do not have an appropriate level of decision capability in favor of the child's interest. The higher the adversity of the consequences, the higher the level of capacity to decide on behalf of the minor, the possibility of intervening with the family, and the state guaranteeing the welfare of the minor.

This article presents the case of a female patient, with whom the treating pediatrician oncologist and the health team of the Hospital Infantil de México Federico Gómez (HIMFG) faced the dilemma of legally intervening with the family in favor of the maximum welfare of the minor versus monitor and participate closely and intervene socially, without disjointing the "family" in a genuinely adverse circumstantial context. We expose how the intervention can occur from support networks parallel to the adversity of the family, with the objective of prioritizing the best interest of the child, without letting a family breakdown and disintegration, even when the family situation can be qualified as catastrophic, outside the legal intervention.

\section{Clinical case}

In 2008, a 9-year-old female patient was taken to the HIMFG by her family, referred from a secondary level pediatric hospital, with a diagnosis of a myeloproliferative disorder.

The following social background of the patient was recorded: 45-year-old mother, illiterate and healthy; 39-year-old father, uneducated, bricklayer assistant, and alcoholic since the age of 8 , who exerts domestic violence according to the mother (Figure 1). She has six brothers; one died at 7 months of age (the cause is unknown). The family lives in the State of Mexico in a 


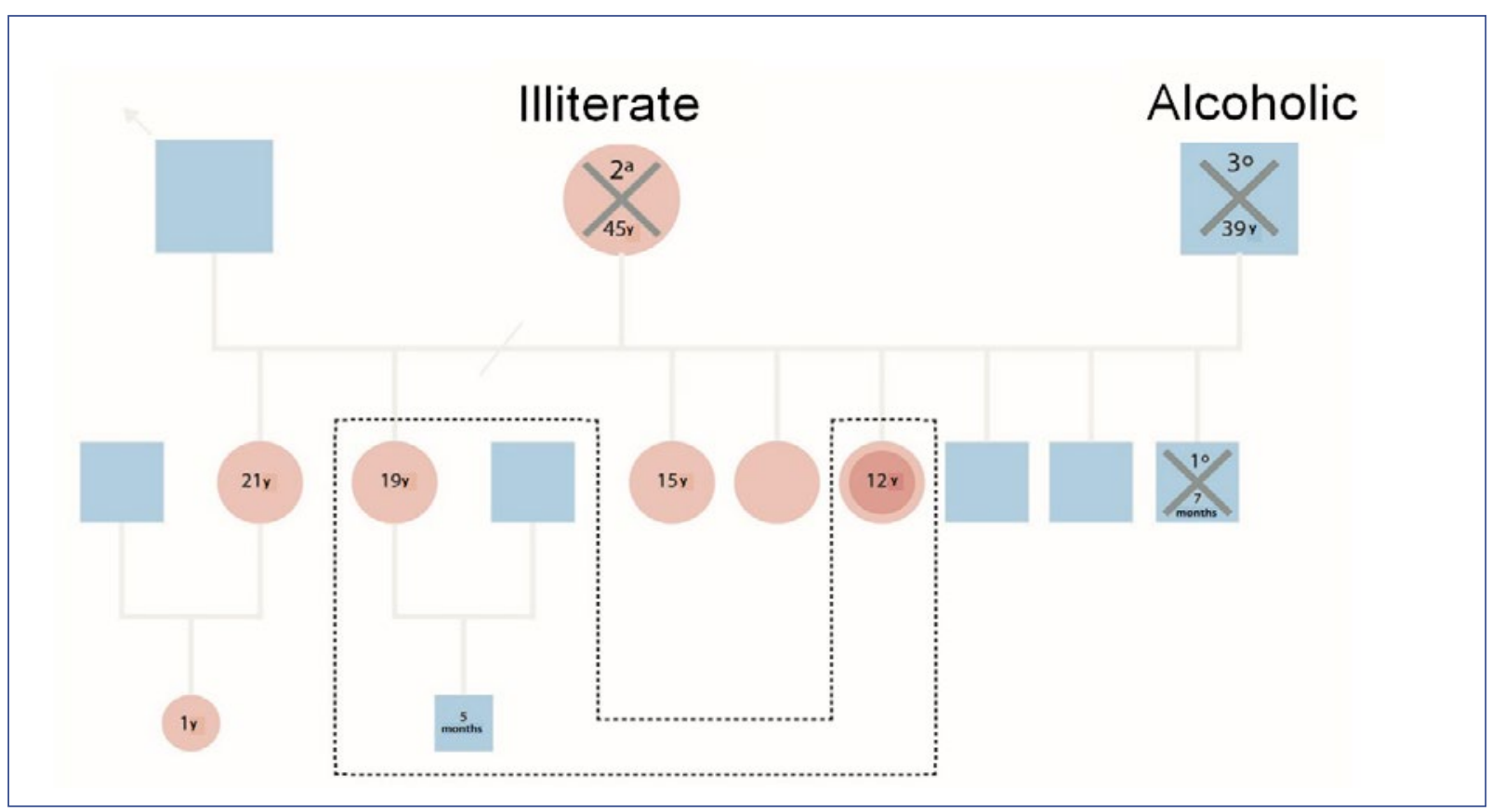

Figure 1. Familiogram of the patient.

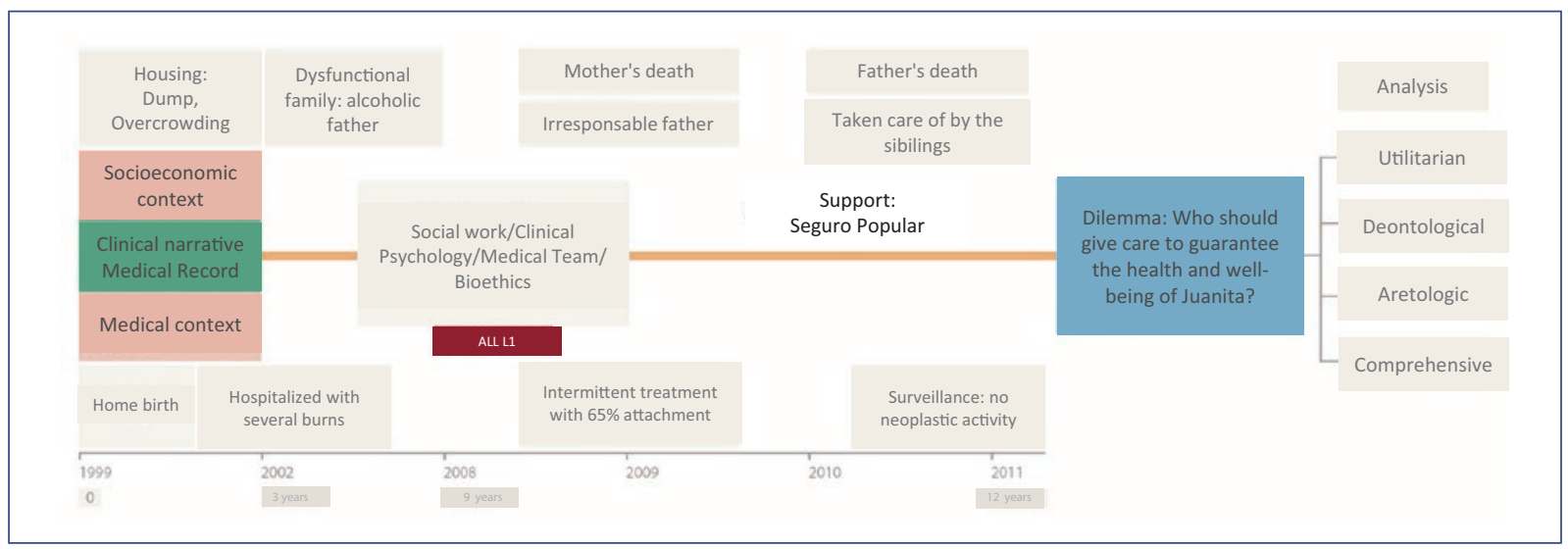

Figure 2. Clinical narrative and bioethical alternatives.

rented house, overcrowding and zoonosis, located near a wastewater passage, within the limits of a municipal garbage dump, which has essential services (water and electricity).

The patient was a full-term pregnancy term product without prenatal control, attended at home by the father, like all her brothers, and has an incomplete immunization schedule. Exclusive maternal breastfeeding until 11 months, adequate psychomotor development, no schooling. The mother reported hospitalization at 3 years of age for burns on lower limbs with hot water used for bathing (Figure 2).
On admission, the patient is diagnosed with an anemic syndrome, infiltrative syndrome, febrile syndrome, myeloproliferative syndrome, and decompensated chronic malnutrition. During the stay, the diagnosis of acute lymphoblastic leukemia LI is established, at high risk for leukocytosis and treatment is initiated. Remission is documented on the $21^{\text {st }}$ day of starting the treatment in its induction phase. A month later, the mother is alerted about the delay in the planned administration of chemotherapy. During the following months, the patient receives treatment of intrathecal chemotherapy (intensification and maintenance) intermittently, canceled twice 
due to the appearance of mild respiratory infectious complications. Bone marrow aspiration is performed for control, and recurrent dermatosis attributable to poor hygiene is treated.

In October 2008, the girl came with an 16-year-old sister, who did not know about the treatment of the patient, for whom support was requested from the department of social work, who asked the presence of the parents for the explanation of the procedure. At the beginning of January 2009, the reinduction stage ended, and the patient attended her appointments intermittently, due to which the administration of chemotherapy is irregular, which is why adherence to treatment is insisted (Fig. 2).

In June 2009, as part of the patient rescue activity, a home visit was made by the social worker. It was reported that the patient belongs to an extended family, which includes other minors and adults, lives in vacant lots where the municipal dump of open garbage sits; they inhabit a jacal built with industrial waste, under conditions of overcrowding, promiscuity, alcoholism, extreme poverty, unhealthiness, and zoonoses and that do not have essential services at home. Those who visit find the mother in poor health, bedridden, unable to take care of herself or her children. A 12-year-old daughter is the one who looks after and cares for the mother, the patient, two younger sisters, and a niece. The father is interviewed, who is dirty and under the effects of alcohol. He is scheduled to be on HIMFG for the same month. The patient came to the hospital accompanied by her father. Consultation is performed with psychology in which it is reported that the father has a borderline intellectual coefficient and does not maintain a good relationship with the patient, in addition to not identifying commitment to the health of his daughter.

In contrast, it is reported that the 10-year-old girl is aware of the treatment and the future consequences of not receiving it correctly. The father is urged about adherence to treatment, and it is emphasized that he must assume responsibility for it. The attending physician agrees with the family that the patient will go to the hospital every Monday, with the purpose of generating a habit that makes it easier for them to keep their appointments.

In the following consultations, the patient was accompanied by two siblings who did not know about the previous treatment or the condition of the same and report that their mother has died (the cause is unknown). DIF is informed to have a closer approach to the family and to avoid the abandonment of treatment.

In July 2009, the situation was notified to the Office of the Child and Family Defense Attorney. One of her sisters (despite being a minor) agrees to participate in the treatment of the patient.

At the end of the year, the case was submitted to the Hospital Bioethics Committee, which recommended that the Department of Social Work and the Legal Department of the Institution coordinate with the DIF offices to contact the father to insist on responsibility for the treatment. It is known that the mother has two daughters of a previous couple; a 21-year-old daughter, who lives with her partner and has a 1-year-old daughter in the family home of the patient and another 17-year-old sister.

After the death of the mother, there are no economic resources or support networks to achieve adherence to treatment; likewise, no one in the family is identified who as responsible for the care of the children. In December 2009, the DIF payed a visit to assign an appointment at the HIMFG for the application of intrathecal treatment. In February 2010, the patient attended for the maintenance chemotherapy application corresponding to week 61 (since her diagnosis), although it actually corresponded to week 36 per application.

In April 2010, after irregular treatment, she came accompanied by her 18-year-old half-sister, since the father had also died. In July of that same year, after the social study of the DIF, the half-sister accepted to act as the legal guardian of the patient. The girl moves to her new home, where she shares a house with her half-sister, her partner, and her 5-month-old son, being her sister's partner who is responsible for paying the expenses of the maintenance. The other brothers were left in the care of their other half-sister of 21 years. The patient's greatest desire was always to stay at home accompanied by her younger siblings, regardless of the social and health situation she was facing. She was able to support her desire to stay at home with clear and well-founded reasons.

In December 2010, during her hospitalization for treatment, she remained without any family member. In November 2011, at 12 years and 10 months of age and with a treatment of 120 weeks, she was left under surveillance with evidence of remission.

\section{Analysis}

A set of questions are presented below to address the dilemma, which allows, in the first place, to specify and characterize the context in which it occurs. Besides, two conceptual approaches are incorporated into their respective ethical framework, which can help in the analysis of the dilemma. 


\section{Ethical discernment by the comprehensive method}

The context in which the dilemma occurs. What are the facts? A 9-year-old female patient with high-risk acute lymphoblastic leukemia. The patient is part of a family in extreme poverty; she attended her consultations with poor hygiene conditions and different caregivers. From the beginning of the treatment, there is no appropriate compliance; only $64 \%$ of the projected therapeutic plan was obtained. The family of the patient is disintegrated, both parents have died, and siblings tried to participate in the patient's care, with their limited resources.

What is the pursued good? The greater good is the protection of the life of the patient in the biological, psychological, and social dimensions.

Who are the beneficiaries of the good? The patient and her family.

Who are the main actors? The patient, her family, and the health personnel of the oncology service.

What are the circumstances, costs, and risks? It is a patient with high-risk acute lymphoblastic leukemia. Her family understands the diagnosis, treatment and its implications in a limited way. The patient comes from a dysfunctional family, whose main trigger is poverty and alcoholism that accelerate the illness and death of both parents, leaving four younger orphan siblings. The only possible support is that of the two half-sisters who are of legal age.

What is the dilemma? The ethical dilemma presented to the health team is to request one of two possible options. That the child's custody was temporarily withdrawn from the family and she was sent to a children's home until the disease is overcome, or to let the patient continue to live in her current conditions and create support and surveillance networks strengthened enough to guarantee that the patient can overcome the disease. The fundamental reason to consider removing the patient from her family is that there is a lack of adherence to the treatment, which risks the child's life. The patient (whose experience in making important decisions is still immature), from the first consultation, expresses in a reasonably explicit way the desire to remain with her parents and siblings.

\section{Ethical strategy to solve the dilemma}

\section{UTILITARIAN PERSPECTIVE}

The more significant benefit or well-being that triggers the intervention of third parties, in this case, is the risk of not being able to recover the health and guarantee the survival of the patient. Therefore, the reason for intervention is by no means trivial. For the health team, the expected benefit of removing the guardianship of the parents temporarily or definitively will overcome the burdens imposed on both the patient and her family. If the potential cost-benefit is also considered, sending the patient to a children's home would be the most judicious since she could complete the treatment successfully and also have the necessary care. However, how much does a children's home in Mexico guarantee the quality care of the patient? Is it not better to strengthen the family and hold it responsible for the care of its members?

\section{DeONTOLogical PERSPECTIVE}

The duty of the health team is not to harm the patient and whenever it is possible to help him, through the recovery of health, as well as to guarantee his survival by fulfilling his duty by seeking the conditions that ensure his survival. This purpose is reinforced by the fact that an interdisciplinary team intervenes in the treatment, which includes the biological, psychological, and social dimensions. The responsible physician and his team must project the needs that arise from the diagnosis, as well as the changes and arrangements that the family will suffer so that the sick member can overcome the adversity. Furthermore, to assess whether the family will be able to face these challenges or if it will require external help to cope with it.

Furthermore, the 9-year-old patient should be consulted about her desire to continue living with her family or to go to a children's home (informed consent) and be able to explain the pros and cons of her decision. However, her opinion at this moment will only be an opinion, because it is impossible to consider her idea as self-determination due to the lack of experience and future projection that a minor can have with 9 years of age.

Throughout the illness, the patient has had to face the death of both of her parents and the lack of resources, both social and emotional to face illness, which at 10 years made her acquire more experience and faculties to be able to express her opinion and be an active part of the decisions about her health if she is allowed and if she agrees.

\section{Aretological perspective}

The essential question is: am I avoiding evil? Something is good if it perfects if it seeks to achieve fullness in the inherent nature of the one who acts. Timely treatment can also help the patient reach her best development; for the health personnel, there will also be an 
improvement since their vocation to the service of life is fulfilled. Priority is given to synderesis, integrity, proportionality, and virtue. From this ethical perspective, a social network would have to be built to support the patient and her family in a comprehensive manner, guaranteeing adherence to treatment, and effective changes in lifestyle. The greatest good for the patient would be to remain with her family in the best possible sanitary conditions, which can be achieved through the construction of a support network for the family. This perspective has the realistic and feasible possibility of carrying out such changes as limitation, which require processes that generate changes from the fundamental roots of her family that entail time and the investment of multiple efforts.

\section{Comprehensive analysis}

Given that, from the aretological and deontological point of view, the most appropriate decision would be to keep the patient with her family, what the health team would have to promote through their support networks would be an improvement of the quality of life of the patient and her siblings (also minors). In the framework of its social context, it is a challenge for the health team to coordinate social efforts so that the patient not only survives the disease but also that she and her siblings have access to education, healthy housing, and safe food. It must be reminded that the ability of a teenager can vary over time according to changes in their condition, so it can be intermittent or fluctuating, but this is the other point to address: the ability of the patient to involve in the decision and that the responsible doctors and the rest of the participants value this intervention (Fig. 2).

\section{Ethical discernment according to Peter Kemp}

From the general framework of the narrative ethics, this approach allows to understand human dignity as a quality that is part of the mental and corporal integrity of the human being ${ }^{9}$. In this approach, four principles are applied that can help the discussion of the cases that are analyzed.

\section{PRINCIPLE OF DIGNITY}

First, this principle affirms that each subject is valuable, that life has no price, and therefore must be respected and protected. Dignity is not based on the place of birth or where you live, it does not depend on who the parents are, on the social or economic level, on education or personal history. In the addressed case, the Oncology Service of the HIMFG organizes a working team with Social Work, Psychology, National System for the Integral Development of the Family (DIF for its Spanish acronym) and the Legal Department, to attend and recover health even in the middle of the indigence, ignorance, and misery in which the patient and her siblings lived. It is based on this principle that physicians should focus their efforts on rescuing this intrinsic value of the patient, without preventing them from taking part in the decisions regarding their life, considering their age, experience, values, and skills as an obvious excuse to invalidate their opinions.

\section{Principle OF INTEGRITY}

Second, the principle of integrity refers to what should not be altered or damaged that has a totality, coherence, and that gives the meaning of unity and a sense of life. From this perspective, the Oncology Service seeks and manages to overcome the problems of the patient's socioeconomic reality to give her the necessary long and expensive treatment. In this case, giving a treatment focused exclusively on curing cancer will mean not giving integral attention to the patient, as well as a lack of vision to anticipate the future without foreseeing subsequent failures secondary to not fully addressing the case.

\section{Principle of VULNERABILITY}

Finally, in relation to the principle of vulnerability in its three dimensions:

a. Biological and Corporal. Given the fragility of organic human life, we try to establish a diagnosis and treatment maintaining the conditions of spacetime continuity and minimum hygiene and nutrition, to avoid later complications.

b. Social. The intention is to preserve a human being with a narrative coherence that receives the goods and services necessary to preserve life, with the purpose of remaking its history from poverty and abandonment to care and protection.

c. Cultural. Given the fragility of the tradition of locally established values, the focus is on finding and giving meaning to life by counting on her sister as a responsible person.

\section{Principle of AUtONOMY}

In this case, it is diminished due to the lack of experience of the patient in decision-making, her age and a 
justified paternalism from the HIMFG. This principle is redirected through the principle of subsidiarity applied by the HIMFG team, so that the teamwork of the different actors that are part of the patient's care come into action, to take it forward, even in spite of a hostile environment. Given the legal presumption of disability, the question to ask ourselves is: how good should her skills and performance should be to make decisions regarding a particular choice and exercise her autonomy, such as to approve or reject the presumption of disability? The welfare of the children, in this case of the patient, will depend more on the objective conditions necessary to foster her development and opportunities than her individual preferences at the time. Therefore, to reject said presumption, it will be necessary to "prove its maturity," that is, its understanding of the nature and objectives of the proposed treatment, understanding that has been proven.

\section{Discussion}

On the horizon between the ethics of the minimum required and ethics of the maximum desirable, bioethics are perceived with a robust aspirational component, a continuous search for the best that health agents can offer, integrated into an interdisciplinary team for each patient. Bioethics thus manages to adapt to scientific and technological changes in constant transformation through the collaboration of innumerable team members, with the desire for perfection and virtue. With this reference, with some principles of reflection and elements of judgment or discernment criteria, action plans are drawn up to decide what is the most convenient for the patient and his family, which allows addressing the ethical dilemmas present in the exercise of the profession.

However, what is an ethical dilemma? For Prilleltensky et al., they are the moral problems found in professional practice, and that cause severe internal conflicts since they involve actions that confront values and that frequently confront colleagues, employees, or different sectors of the social fabric ${ }^{10}$.

These dilemmas have been classified into personal values conflicts, conflicts with other professionals, conflicts with patients and, finally, with organizations.

It is usual to find, in pediatric practice (more than in other specialties), situations in which the health personnel judge the performance of the patient's parents as insufficient or inappropriate about their ill children. The physician, as responsible for the child in the process of illness, sometimes requires to exercise a non-interventionist judgment on the behavior of the parents and communicate it to promote improvements. However, if no changes are observed, it must involve other members of the institution and extrainstitutional (if the case warrants), to intervene the family as a team for the welfare of the child.

The Central Juvenile Prosecution Office is the authority empowered to intervene in cases in which a child is found in a situation of harm, risk, or danger and that is required for their protection, their channeling to a temporary shelter or public or private institution of social assistance. The purpose of the Office of the Prosecutor is to safeguard at all times the best interests of the minor, maintaining his right to be in the care of his parents. When this is not possible, because the parents were probably responsible for a conduct against the integrity of the minors or because they could not be located, they must proceed in accordance with the provisions of articles 303 and 305 of the Civil Code for the Federal District, regarding the order in which the relatives have the obligation of the care and nutrition toward the minors.

Only when it is not possible to deliver the child to their parents or relatives, in accordance with the previous sections, the Central Juvenile Prosecution Office must, under its strict responsibility, channel him for care and attention to a temporary shelter of the Attorney General's office or the corresponding public or private social assistance institution, in accordance with the following: in the case of children from 0 to 12 years old physically available, they shall be channeled to the Temporary Shelter of the Federal District's Attorney General's Office.

We must not forget that, in Mexico, the situation for children who are referred to an institution of this nature is complicated, because not only they are without the protection of their parents but sometimes also from that of the state since Mexico is ranked second in Latin America's in frequency of abandoned children. The state can be ignorant in fulfilling its obligation to regulate and supervise the operation of public and private centers where thousands of children have been left for their care, due to the overpopulation. For 30 years, children have been sent to shelters supported by civil organizations due to the inability of the state and society to face an increasing problem, children that are often victims of orphanage, violence, and abuse $e^{7,11}$.

The threshold, for the state to mediate should be the harm to the minor; that is, when "maleficence" is identified. However, this does not imply the mandatory withdrawal of the custody or guardianship of the minor; before that, family strengthening should be attempted 
through interventions of medium and high complexity, when the case allows it. "The fundamental guideline is the priority of the child's benefit over any other interest and cannot have a rigid and inflexible definition," and is the guiding and directing principle for conduct both the authorities and society to adopt the necessary measures to make respect the fundamental rights of minors, always taking into account that each child, in each conflict, "deserves a specific and different solution according to each situation ${ }^{12}$."

Parents are who influence decisions about the type of actions that could benefit the child most often, and these decisions frequently have an impact beyond the present. That is why physicians have the responsibility to formulate an independent judgment about the best interest of the patient, as well as to evaluate and question, within a future projection, parents decisions.

In the case at hand, the lack of essential care was evident, given the severity of the disease of the patient. The family survived under conditions of extreme poverty and neglect; however, the illness of the patient was the trigger for the intervention in the situation of this family. If it was not for the disease, would the children would have remained in the same state of abandonment? Parents cannot be blamed for neglect or negligence care; within the limits of their social, economic, and intellectual possibilities, they did their best to fulfill the treatment (They were the ones who took their daughter to the hospital and who complied with the referral to the third level hospital). The parents did their best for their daughter, that is undeniable, but the environment was so hostile that it hindered the desire for the patient's health.

The lack of adherence to medical indications in the face of a life-threatening illness, constituted a situation that deserved urgent intervention in the family because it was about to collapse, but why wait for the threat to be vital to intervene? Alternatively, was it not the lack of education of the children a reason to have intervened earlier?

The case was submitted to the Hospital Bioethics Committee to receive a recommendation focused on the best interest of the child and to evaluate the degree and magnitude of intervention that the hospital should have in the family.

As discussed above, when the adversity or the harm to the minor is higher, the intervention that third parties must have in the care and attention will also be more significant. It means that it should not always be necessary to interfere as much in the freedom that the family has in the care of its members, but it will depend on the gravity of the damage that is being caused to the child in the present or for his future, to prevent further damage.

The truth is that the lack of adherence to caregivers, in a life-threatening disease, is considered very serious and the case must be thoroughly analyzed, integrating all the points of view; therefore, in this case, the support of the Hospital Bioethics Committee was required.

For the committee, it is necessary to recognize the criteria of the children's capacity to decide on their medical care when they wish and can do it themselves; nothing in our analysis implies forcing the child to decide, be pressured or encouraged to choose on his or her care when he or she does not wish to do so. A child can feel emotionally capable of making decisions if in the area of his health he does not feel empowered to take responsibility for such a decision, then, although his other capacities are well developed, it could be harmful to assume that responsibility. The patient in our case had a particular situation, since she was not neglected, orphan, or in a street situation and our duty is to ensure that children are not "institutionalized" so that they can live in a family, whether their own or adopted, in appropriate conditions, and well-being, with the intervention of third parties when required. Therefore, when the responsible physicians were questioned about the opinion of the girl, they expressed that her will was to be at home with her family. The patient and her sisters were given the possibility of staying in another place where they had "better" services (such as food, bath, and bed) and that guaranteed her attendance to her consultations and chemotherapy, but she and the family were insistent on staying in their house, in the company of her siblings. From an evaluation by the Psychology Department, it was concluded that the patient was capable to participate in the decisions regarding her treatment since she had the faculty to communicate openly, she understood the information (described in terms that she could understand), the repercussions and consequences of not receiving her treatment (she had already experienced the death of her parents and realized that leukemia could kill her) and she could explain and justify the motive for her decision, as well as to articulate possible realistic solutions to the problem.

It should be noted that this assessment was specific because there is a significant variation among children of the same age and sex. Therefore, the committee warned that the patient would be given appropriate and pertinent support to ensure continuity in her treatment, and that, in case of not achieving the objective, it would 
be needed to intervene legally to place the patient under the custody and guard of the state. While this was not the situation, it would be closely monitored and supported by hospital and DIF staff.

The Hospital Bioethics Committee is an autonomous, interdisciplinary, plural, and consultative body where reflection, deliberation, and education are carried out in an environment of freedom and tolerance, where the conflicts of values and bioethical principles that arise during the process of medical attention are systematically analyzed, but this opinion cannot be imposed on medical decisions. Consequently, the HIMFG Committee recommended that the doctor in charge give notice to the Legal Department of the Institution, and kept in contact with the DIF through Social Work of the Onco-Haematology Department, which, in turn, put into operation the weekly home visits and follow-up appointments through phone calls.

The legal department considered that the minor was at risk of death due to lack of care, as well as that it was in the desire of the family to grant them. It is indisputable that the parents and siblings were in favor of the best interest of the patient; however, their social situation prevented them from doing it correctly.

The courts recognize that, at present, the alternatives to taking care of these patients by the state are not a guarantee for their better welfare.

Family uprooting has negative consequences for psycho-emotional maturation in childhood and adolescence. The family, in any form, without a doubt is the best place for a human being to be born, grow up and develop as a healthy individual and to be a socially productive person. Current legislation in Mexico stipulates that if potentially available relatives are found to take charge of the minor, parental authority shall not be withdrawn, in the hope that the members of that family may respond as expected to the common good of the society. The law does not describe in detail criteria on the conditions of life that must be offered to the child, which is understandable due to the different situation in which the children of our society can be found. It is also considered that a vast majority of children in our country live in poverty, which is sometimes extreme and the most effective solution is not the withdrawal of custody, but the early intervention of society to strengthen families and end the cancer that is poverty and as a direct consequence the partial or total neglect of minors.

The Working Group on Ethical Dilemmas in Pediatrics was integrated in March 2011; since then they had held regular meetings to achieve their goals. The group is composed on a multidisciplinary team (doctors, philosophers, and academics) and interinstitutional (HIMFG, Universidad Panamericana, Instituto Panamericano de Alta Dirección de Empresas [IPADE], Hospital General de México Dr. Eduardo Liceaga, Universidad Anáhuac and Instituto Mexicano del Seguro Social). The primary purpose of the working group is to help clarify the ethical dilemmas that arise in everyday pediatric practice, as well as to pay attention to the search for an appropriate ethical discernment in representative cases.

\section{Ethical disclosures}

Protection of human and animal subjects. The authors declare that no experiments were performed on humans or animals for this study.

Confidentiality of data. The authors declare that they have followed the protocols of their work center on the publication of patient data.

Right to privacy and informed consent. The authors declare that no patient data appear in this article.

\section{Conflicts of interest}

The authors declare no conflicts of interest.

\section{References}

1. Lewis C.G. A comparison of minors' and adults' pregnancy decisions. Am J Orthopsychiatry. 1980;50:446-453.

2. Melton GB, Koocher GP, Saks MJ. Children's competence to consent. US: Springer; 1983. p. 84.

3. Piaget J. El criterio moral en el niño. Barcelona: Fontanell; 1971.

4. Capron AM. The Competence of Children as Self-deciders in Biomediccal Interventions. In: Gaylin W, Mcklin R, editors. Who speaks for the child? The problems of proxy consent. New York: Plenum Press; 1982. p. 94.

5. De Lora P. Autonomía personal, intervención médica y sujetos incapaces. Universidad Autónoma de Madrid. Enrahonar. 2008;40-41:123-40.

6. Gracia Guillen D. Sánchez-Jacobo M. Bioética y Pediatría Proyecto de Vida Plena. Madrid: Sociedad de Pediatría, Madrid y Castilla La Mancha. 2010; págs. 29-38.

7. UNICEF. Convención sobre los derechos del niño. Available at: https:// www.unicef.es/causas/derechos-ninos/convencion-derechos-ninos

8. Shoeman F. Parental discretion and children's rights: back-ground and implications for medical decision-making. J Med Philos. 1985;10:45-61.

9. Kemp P. La mundializacion de la ética. México: Distribuciones Fontamara; 2007.

10. Prilleltensky I, Sánchez-Valdés L, Rossiter A, Walsh-Bowers R. Applied ethics in mental health in Cuba: Part II. Power differentials, dilemmas, resources and limitations. Cuba: Lawrence Erlbaum Associates, Inc., Ethics \& Behavior. 2002;12:243-260.

11. Guadarrama-Orozco JH, Garduño EJ, Vargas LG, Viesca TC. Consentimiento informado y rechazo de los padres al tratamiento médico en edad pediátrica. El umbral de la tolerancia médica y social. Parte I. Bol Med Hosp Infant Mex. 2015;72:208-14.

12. Pinheiro PS. Informe del experto independiente para el estudio de la violencia contra los niños. Asamblea General de las Naciones Unidas. Nueva York: UNICEF; 2006. p. 19. 